\title{
Multidimensional Model of Racial Identity: A Reconceptualization of African American Racial Identity
}

\author{
Robert M. Sellers \\ Department of Psychology \\ University of Michigan
Mia A. Smith and J. Nicole Shelton
Department of Psychology
University of Virginia \\ Stephanie A. J. Rowley \\ Department of Psychology \\ University of North Carolina \\ Tabbye M. Chavous
Department of Psychology
University of Virginia
}

\begin{abstract}
Research on African American racial identity has utilized 2 distinct approaches. The mainstream approach has focused on universal properties associated with ethnic and racial identities. In contrast, the underground approach has focused on documenting the qualitative meaning of being African American, with an emphasis on the unique cultural and historical experiences of African Americans. The Multidimensional Model of Racial Identity (MMRI) represents a synthesis of the strengths of these two approaches. The underlying assumptions associated with the model are explored. The model proposes 4 dimensions of African American racial identity: salience, centrality, regard, and ideology. A description of these dimensions is provided along with a discussion of how they interact to influence behavior at the level of the event. We argue that the MMRI has the potential to make contributions to traditional research objectives of both approaches, as well as to provide the impetus to explore new questions.
\end{abstract}

African Americans' experiences in the United States differ significantly from those of members of other ethnic groups. Although many ethnic groups have experienced discrimination and oppression in the United States, the form of oppression that African Americans have faced is unique. While the worthiness of other ethnic groups has often been questioned upon their arrival in American society, no other groups' humanity was denied them by the U.S. Constitution. African Americans were defined legally as property by the United States government for almost a century. For nearly 100 years after the end of slavery, laws were enacted with the expressed purpose of making social contact between Whites and African Americans illegal. Such laws effectively relegated African Americans to the status of second-class citizens. Because they were brought to the United States against their will and

Requests for reprints should be sent to Robert M. Sellers, Department of Psychology, University of Michigan, Ann Arbor, MI 48109-1109. E-mail: rsellers@umich.edu. systematically deprived of access to their indigenous culture, African Americans were not afforded the choice of whether to assimilate into the new culture or retain their indigenous culture. As a result, traditional African culture has had to be grafted onto the cultural practices of the European/American society to form an original cultural expression. The African American celebration of Kwanza is a good example of this union.

As a result of their experiences with oppression in this society, the concept of race has historically played a major role in the lives of African Americans. Although race has dubious value as a scientific classification system, it has had real consequences for the life experiences and life opportunities of African Americans in the United States. Race is a socially constructed concept which is the defining characteristic for African American group membership. This does not deny the importance of both traditional African and African American culture in the phenomenon of racial identity in African Americans. However, American society's somewhat arbitrary categorization of individuals into 
this racial group has resulted in the psychological unification of many individuals who vary a great deal in their experiences and cultural expressions. The fact that the experiences of African Americans are heterogeneous has resulted in variability in the significance and qualitative meaning that they attribute to being a member of the Black racial group. For instance, some individuals place little significance on race in defining who they are, while others may see their racial membership as the defining characteristic of their self-concept. Even when individuals place similarly high levels of significance on race in defining themselves, they may differ a great deal in what they believe it means to be Black. ${ }^{1}$ One individual may believe that being Black means congregating among other Blacks, while another may believe being Black means that one should integrate with Whites. It is the significance and meaning that African Americans place on race in defining themselves that we refer to as racial identity. ${ }^{2}$

In this article, we introduce a new model of African American racial identity - the Multidimensional Model of Racial Identity (MMRI). This model provides a conceptual framework for understanding both the significance of race in the self-concepts of African Americans and the qualitative meanings they attribute to being members of that racial category. Along with this conceptual framework, we propose a mechanism by which racial identity influences individuals' situational appraisals and behaviors. Before presenting the model, we highlight the potential contributions of the MMRI and place it within its historical context by presenting a brief historical review of the way in which African American racial identity has been conceptualized and investigated in the psychological literature. Next, we discuss how contemporary researchers have begun to conceptualize ethnic identity to incorporate both the significance and the meaning of their ethnic group membership. We will then describe the four dimensions that comprise the

\footnotetext{
'We purposefully make a distinction in our usage of the terms Black and African American. The term Black is used as an ambiguous category that may or may not be inclusive of all persons of African descent, depending upon the individual's viewpoint. Some African Americans conceptualize the Black reference group as a group that is made up of African Americans only. Other African Americans may hold a more Pan-African view of the Black reference group, in which anyone of African descent is considered to be Black. Thus, we use the term Black when referring to the individuals' own phenomenological view of the make-up of their reference group. In contrast, we use the term African American to refer to those individuals of African descent who have received a significant portion of their socialization in the United States. Thus, the term African American is culturally bound to a group of people within the context of American society.

${ }^{2}$ Although some researchers have argued against the term racial identity in favor of the term ethnic identity to describe group identity within African Americans (e.g., Smith, 1989), we believe the importance of the concept of race in the experiences of African Americans makes the former term preferable.
}

MMRI as well as some preliminary evidence of its operationalization. Next, we discuss how both the significance of race and the meaning of race interact to influence behavior at both the molecular and molar level. Finally, we conclude with a discussion of the contributions of the MMRI to our understanding of African American racial identity.

\section{Brief History of Racial Identity Research}

Racial identity has been one of the most heavily researched areas that focuses on the psychological experiences of African Americans. Since its infancy, racial identity researchers have grappled with the significance and meaning of the construct (Cross, 1991). Much of the early research viewed African American racial identity within the context of this group's stigmatized status in American society, with little regard for the role of culture (Clark \& Clark, 1939; R. Horowitz, 1939). Gaines and Reed $(1994,1995)$ refer to this research tradition as the mainstream approach. This approach primarily has focused on the universal aspects of group identity, using African Americans as a specific example. In the. late 1960s another group of psychologists, primarily African Americans, began to redefine African American racial identity with particular emphasis on the uniqueness of their oppression and cultural experiences. This research constitutes what Gaines and Reed $(1994,1995)$ refer to as the underground perspective. ${ }^{3}$ Although the mainstream approach owes its roots to the work of Gordon Allport (1954), the underground approach has a lineage that dates back to the pioneering work of W. E. B. DuBois (1903).

Initially, Gaines and Reed $(1994,1995)$ distinguished between the mainstream and underground approaches in their analysis of the research literature on prejudice. In their analysis, these investigators suggested that the mainstream approach is concerned primarily with examining universal cognitive and affective processes (biases and errors) to explain how and why individuals (regardless of race) exhibit prejudicial behavior. This approach suggests that any group can act in a prejudicial manner or display in-group bias. In contrast, the underground (or Afrocentric) approach emphasizes the historical and cultural factors associated

\footnotetext{
${ }^{3}$ Gaines and Reed $(1994,1995)$ use the term underground to reflect the fact that the research from this approach has traditionally received relatively little recognition from the broader psychological community. Like Gaines and Reed, we do not wish to convey secretiveness or subversive activity when we use the term underground. The researchers within this approach have held a continuing public discourse regarding their work that has been presented and published in sources that are available to everyone. The applicability of the term underground comes from the unfortunate reality that the scholarship has been virtually ignored by mainstream psychology.
} 
with African Americans' experiences in the United States. Prejudice is seen as more than an error or bias in cognitive processing with an associated affective response. The underground approach views racial prejudice as a by-product of America's history of slavery and exploitation. Racial prejudice is viewed within the context of the White society's need to resolve the dissonance between the high moral ideas that embody being an American and America's immoral treatment of African Americans. In actuality, much of Gaines and Reed's (1994, 1995) discussion of prejudice focuses on the differences in Allport and DuBois's conceptualization of the identity development of African Americans in the face of prejudice.

\section{Mainstream Approach to African American Racial Identity}

Allport (1954) maintained that living in a racist environment must have negative consequences for the African American psyche. As a result, he assumed that African Americans were forced to either devalue aspects of themselves that reminded them of the stigma of being African American, or devalue the broader society for its prejudice against them, in order to function. This notion of an unhealthy, stigmatized identity was consistent with the predominant conceptualizations of the African American self-concept prior to the late 1960s (Clark, 1965; R. Horowitz, 1939; Kardiner \& Ovesey, 1951). Subsequently, much of the early research on African American racial identity from the mainstream perspective presumed that self-hatred was a significant aspect of the African American self-concept (Cross, 1991).

As the mainstream approach has matured, much of the focus has been on understanding the cognitive processes and structures of different group (or social) identities within the self-concept (e.g., Cheek \& Briggs, 1982; Gurin \& Markus, 1988; Hogg, 1992; Markus, 1977; Oakes, Haslam, \& Turner, 1994; J. C. Turner \& Oakes, 1989) while ignoring the unique experiences of each group. For mainstream researchers, racial identity within African Americans is simply one example of these processes. The focus has been on assessing the common psychological structures associated with group identities of different racial/ethnic groups. Based on this focus, mainstream researchers tend to employ measures of group identity that are applicable to members of a variety of groups (e.g., Luhtanen \& Crocker, 1992; Phinney, 1992). For example, Luhtanen and Crocker (1992) developed a collective self-esteem scale that measures individuals' attitudes and feelings about a group with which they strongly identify. The reference group individuals choose may be based on race, gender, ethnicity, region, occupation, or something else. Presumably, persons' responses to a particular group are comparable to the responses of another group they may select or even to other persons' responses to different groups. Phinney's (1990, 1992) measure of ethnic identity emphasizes a universal process that is associated with individuals' development of an ethnic identity. Phinney de-emphasizes the unique history and experiences associated which each ethnic group in favor of promoting a generic model that emphasizes the similarities across ethnic groups so that comparisons can be made across them.

The mainstream approach to racial/ethnic identity has tended to focus on the significance of race or ethnicity in individual lives. For instance, both Phinney (1992) and Crocker (Crocker \& Luhtanen, 1990) have a concept in their model that deals with the importance individuals place on their racial/ethnic group membership. Crocker and her colleagues address this dimension of racial identity with their membership subscale in the Collective Self-Esteem measure (Luhtanen \& Crocker, 1992). Phinney also measures a similar construct in her Multi-Group Ethnic Identity measure (Phinney, 1992). To their credit, Crocker and her colleagues distinguish between the significance of race to an individual's self-concept and the affective and evaluative feelings that the individual holds for his or her racial/ethnic group by delineating a separate construct that they call private self-esteem. Cross (1991) notes the historical importance of making such a distinction in investigating racial identity and self-esteem in African Americans as some of our recent research on the relationship between racial identity and self-esteem suggests (Rowley, Sellers, Chavous, \& Smith, in press).

In its focus on universal properties and its emphasis on the significance of a group identity to an individual, the mainstream approach also has produced a great deal of research describing contexts in which a particular group identity is most likely to be salient (e.g., Abrams, Thomas, \& Hoggs, 1990; Cota \& Dion, 1986; Kite, 1992; McGuire \& McGuire, 1982; J. C. Turner, Oakes, Haslam, \& McGarty, 1994). Research in self-categorization and social identity suggests that the social context of a particular situation can make various aspects of an individual's identity more or less accessible to them (e.g., Abrams et al., 1990; Cota \& Dion, 1986; Kite, 1992; McGuire, McGuire, Child, \& Fujioka, 1978). Distinctiveness theory (McGuire et al., 1978) states that when one is confronted by a complex stimulus, one notices a given characteristic of the stimulus to the extent that it is distinctive in the usual environment. In other words, McGuire and colleagues have consistently found distinctiveness to be relevant in relation to ethnicity and gender, as well as to a host of other factors such as age, birthplace, weight, hair color, and eye color (Kite, 1992; McGuire et al., 1978; McGuire, McGuire, \& Winton, 1979; McGuire \& Padawer-Singer, 1976).

The mainstream approach also has provided substantial evidence that making a group identity salient 
has consequences for the way in which individuals will perceive persons who are outside of their group (e.g., Crocker \& Luhtanen, 1990; Crocker \& Major, 1989; Crocker \& Swartz, 1985; Jackson \& Sullivan, 1987; McCall \& Simmons, 1978). When the context is manipulated to make group membership salient, individuals are likely to evaluate fellow members of their group more favorably than individuals outside their group. They are also likely to devalue members of the outgroup. Membership in a stigmatized group also influences the way individuals interpret negative feedback (Crocker \& Major, 1989). Members of a stigmatized group are more likely to attribute negative feedback to prejudice than others in situations in which such an attribution is reasonable. Such external attributions seem to serve a protective function for the self-esteem (Crocker \& Major, 1989).

As a whole, the mainstream approach has produced a significant body of research delineating the underlying structure of identity for different groups. However, in producing this important information, this approach has, until recently, placed very little attention on the qualitative meanings associated with particular ethnic and racial identity. As a result, the mainstream approach has provided a view of African American racial identity that has emphasized the stigma associated with having African features in this society. In some instances, mainstream researchers have acknowledged the protective qualities associated with African American racial identity (e.g., Crocker \& Major, 1989), but even this acknowledgment is based on a view of African American racial identity that focuses on the stigma attached to the identity, as opposed to the experiential properties associated with the unique historical and cultural influences associated with the African American experience.

\section{Underground Approach to African American Racial Identity}

In contrast to Allport, DuBois (1903) did not view the African American self-concept as necessarily being damaged. Although he felt that the racial oppression African Americans faced played a significant role in the development of their self-concepts, he also recognized that there were cultural influences that had a direct positive influence on African American ego development. Thus, DuBois recognized that African Americans could forge a healthy, strong self-concept even with the stigma of being devalued by the larger society. From these theoretical roots, the underground approach to racial identity developed. As noted earlier, some mainstream research has recognized that racism has not resulted in systematic self-hatred in African Americans (e.g., Crocker \& Major, 1989); however, there is a clear difference between the two approaches in the emphasis that is placed on the role that history and culture play in the qualitative and experiential meaning associated with being Black.

The underground perspective emphasizes the specificity of African American racial identity. The focus has been on providing a description of what it means to be Black. In other,words, the underground approach has provided identity profiles regarding individuals' attitudes and beliefs associated with their membership in the Black race. These profiles may differ as a function of identity development (Cross, 1971, 1991; Milliones, 1976; Parham, 1989) or exposure to a nurturing sociocultural environment (Baldwin, 1984; Kambon, 1992). Nonetheless, an optimal set of beliefs and attitudes regarding one's race are either implicitly or explicitly stated. Researchers differ in their criteria for determining what constitutes an optimal identity. This criteria ranges from an ability to survive in a racist environment (Parham, 1989) to a biogenetically predetermined state of identity (Baldwin, 1984; Kambon, 1992).

DuBois (1903) eloquently articulated the double consciousness that resulted from the inherent struggle of being both a "Negro" and an American. Because of the inherent conflict between America's overwhelmingly negative view of the Negro and the Negro's own view of him or herself, the essential task of healthy ego development in African Americans becomes the reconciliation of the discrepancy between his or her African self and his or her American self. Not surprisingly, the tension between the individual's "blackness" and the broader White society plays a central role in the way theorists from the underground perspective attempt to define the meaning of being Black. However, there is great variability in the way that this tension is conceptualized in definitions of what it means to be Black. Some theorists view identification with one's blackness and identification with the broader White society as being two separate endpoints on a single continuum (e.g., Baldwin, 1984). Others view them as two separate dimensions on which individuals fall (e.g., Boykin, 1983). Still others conceptualize exceptionally strong identification with all things Black as being an important step within the process of developing an integrated identity (e.g., Cross, 1991). Theorists from the underground approach also recognize that the meaning of being Black is not only influenced by experiences of racism, but also incorporates cultural experiences from African Americans' historical and contemporary experiences in America and Africa (e.g., Azibo, 1989; Baldwin, 1980, 1984; Cross, 1971, 1991; Kambon, 1992; Milliones, 1976; Smith, 1991; J. L. White \& Parham, 1990). As a result, many Afrocentric theorists consider it to be inappropriate to use models based on the experiences of other ethnic groups to explain the experiences of African Americans (Akbar, 1984; Azibo, 1991; Baldwin, 1984). 
Perhaps the most widely used model of African American racial identity within the underground perspective is Cross's model of Nigrescence (Cross, 1971, 1991). The Nigrescence model describes five stages of racial identity development that African Americans experience as they develop a psychologically healthy Black identity (Cross, 1971, 1991; Helms, 1990; Parham, 1989). Although the model has been adapted to investigate the group identities of members of other groups, the Nigrescence model was originally proposed to describe the unique cultural and structural experiences associated with becoming Black in the United States (Cross, 1971). Recently, Cross (1991) revised the model and broadened each stage to include more diverse experiences. Briefly, in the first stage, preencoun$t e r$, individuals do not believe that race is an important component of their identity. This may include an idealization of the dominant White society or simple placement of more emphasis on another identity component such as gender or religion. Individuals in the second stage, encounter, are faced with a profound experience or a collection of events directly linked to their race. This experience encourages individuals to reexamine their current identity and find or further develop their Black identity. This experience can be either positive or negative (Cross, 1991). The third stage, immersion/emersion, is described as being extremely proBlack and antiwhite. Externally, individuals are obsessed with identifying with Black culture, but internally they have not made the commitment to endorse all values and traditions associated with being Black. The fourth stage, internalization, is characterized by having a feeling of inner security and satisfaction about being Black. Moreover, individuals at this stage tend to have a less idealized view regarding the meaning of race. They are able to see both the positive and negative elements of being Black or White. Internalization-commitment, the final stage, represents those individuals who translate their internalized identities into action.

Parham and Helms (1981) developed the Racial Identity Attitudes Scale (RIAS) to operationalize the Nigrescence model. The RIAS measures attitudes that are representative of attitudes individuals are likely to hold toward the self, Blacks, and Whites as they transverse through the four stages. Attitudes are predicted to change from antiblack or low race salience (preencounter); to attitude flux (encounter); to pro-Black with reference to antiwhite attitudes (immersion-emersion); to pro-Black without reference to White attitudes. The latest version of the RIAS is a 50-item scale in which respondents use a 5-point Likert-type scale ranging from 1 (strongly disagree) to 5 (strongly agree) to indicate the extent to which each item represents their attitudes (Helms \& Parham, 1990). There has been some concern regarding the reliability of the subscales (Ponterotto \& Wise, 1987), and some authors have questioned whether the use of an attitude scale is able to capture the complexity of African American racial identity (Akbar, 1989).

Whereas the mainstream approach has focused primarily on questions regarding the internal validity of the identity processes, the underground approach has been primarily concerned with exploring the predictive validity of their models. For example, much of the research using the RIAS has investigated the correlation between individuals' scores on the four subscales of the RIAS and such phenomena as demographic background (Parham \& Williams, 1993), attitudes regarding utilizing counseling services (Austin, Carter, \& Vaux, 1990; Helms, 1984; Parham \& Helms, 1981), self-actualization (Parham \& Helms, 1985), and ego functioning (Marriette, 1990). Meanwhile, relatively little empirical research has directly investigated the processes proposed in the Nigrescence model (Sellers, 1993). Little longitudinal research has been produced that demonstrates the validity of the concept of individuals' cycling through the four stages proposed by the model. Similarly, much of the research using Baldwin's (1984) African Self-Consciousness model has focused on its ability to predict Afrocentric-related behavior and attitudes to the neglect of research questions regarding the underlying assumptions of the model (e.g., Baldwin, Brown, \& Rackley, 1990; Baldwin, Duncan, \& Bell, 1987; Baldwin \& Hopkins, 1990). Thus, the underground approach has produced research that has provided relatively strong evidence that the meaning that African Americans hold for their racial identity plays an important part in their lives but has generated relatively little empirical evidence supporting the existence of the internal processes and structures proposed in their conceptual models.

The mainstream perspective and the underground perspective provide very different views of African American racial identity. While there is some overlap between the two perspectives, the two approaches differ in the types of research questions, methodologies, and results they have yielded. The mainstream approach, with its focus on process and structure, provides a framework through which African American racial identity can be viewed in the context of other identities individuals may possess. Meanwhile, the underground approach provides a framework for studying the cultural and experiential influences which comprise the qualitative aspects of African American identity. It also provides a metric in which to understand individual differences in the level of identification with the group.

It is obvious that the two approaches to studying group identity are more complementary than contradictory. Because they have different foci, an integration of the two approaches provides an opportunity to generate a more comprehensive understanding of African American racial identity than either approach could provide alone. We attempted to achieve such an inte- 
gration by introducing the Multidimensional Model of Racial Identity (MMRI). The MMRI represents an amalgamation of a number of existing theories on group identity that is sensitive to the historical and cultural experiences that make racial identity a unique form of group identity for African Americans.

\section{Assumptions of the MMRI}

In her review of the adult ethnic identity research, Phinney (1990) noted that nearly two-thirds of the studies failed to define racial or ethnic identity explicitly. The MMRI defines racial identity in African Americans as the significance and qualitative meaning that individuals attribute to their membership within the Black racial group within their self-concepts. This definition can be broken into two questions: "How important is race in the individual's perception of self?", and "What does it mean to be a member of this racial group?" The MMRI attempts to address these questions.

With these questions in mind, four assumptions undergird the MMRI. Unlike the assumptions underlying some underground models (Kambon, 1992), these assumptions are all testable, thereby providing a means by which to assess the validity of the conceptual model (see Sellers, 1993). First, the MMRI assumes that identities are situationally influenced as well as being stable properties of the person. Some theorists have argued that the self may be a situationally determined construct (J. C. Turner et al., 1994), whereas other researchers have focused on the stable properties of identity (Markus, 1977; Swann \& Read, 1981). The MMRI takes a position similar to that of Stryker and other identity theorists in that identity has both properties (Markus \& Kunda, 1986; Stryker \& Serpe, 1982, 1994). Specifically, racial identity in African Americans has dynamic properties that are susceptible to contextual cues and allow the stable properties of the identity to influence behavior at the level of the specific event. At the same time, there are also stable properties of racial identity that allow us to see differences in the qualitative value and significance individuals place on the role race plays in how they define themselves. These stable qualities of racial identity are not immutable. They may gradually change throughout the life span as a result of a cumulative influence of the social environment and/or developmental forces. More intense situations or experiences such as those characterized by the encounter stage of the Nigrescence theory may also result in lasting changes in the significance and meaning of race in an individual's life (Cross, 1971, 1991).

A second assumption of the MMRI is that individuals have a number of different identities and that these identities are hierarchically ordered (Markus \& Sentis, 1982; McCall \& Simmons, 1978; McCrae \& Costa, 1988; Rosenberg, 1979; Stryker \& Serpe, 1982; 1994).
Although a number of different criteria can be identified in the literature as placing various identities within a hierarchy (McCall \& Simmons, 1978; Rosenberg, 1979; Stryker \& Serpe, 1994), the MMRI uses criteria that are most consistent with those used by Rosenberg (1979). In examining the hierarchy of identities, the MMRI focuses on the importance that the individual places on race in defining him or herself. By explicitly conceptualizing racial identity as only one of many identities within the self-concept, the MMRI provides the opportunity to investigate race within the context of other identities such as gender and occupational identity. The relative importance of race compared to other identities may have important implications for the qualitative meaning that a person ascribes to being African American. For instance, an African American woman for whom both gender and race are important to her definition of self is more likely to incorporate gender in her conceptualization of what it means to be Black than an African American woman for whom gender is not a central aspect of her identity.

A third assumption of the MMRI is that individuals' perception of their racial identity is the most valid indicator of their identity. Although the MMRI recognizes the role that societal forces plays in shaping the self, the emphasis is clearly on the individual's construction of his or her identity. Thus, the MMRI takes a phenomenological approach toward studying racial identity that focuses on the person's self-perceptions (Jones \& Gerard, 1967; Weiner, 1974). Some researchers have chosen to focus on behavioral indicators over subjective perceptions of the self as a less contaminated approach to understanding the self (Stryker \& Serpe, 1994; R. Turner, 1978). Because the MMRI is, by definition, interested in the individual's own perceptions of the significance of race in his or her own definition of self, behavioral indicators are less desirable than the person's self-report. This does not mean that we expect no relationship between self-reported perceptions and overt behavior. For the most part, racerelated behaviors and activities should be highly correlated with the person's subjective beliefs about the importance of race in their self-concept (Phinney, 1992). However, because overt behavior associated with a particular identity is also constrained by contextual factors (Stryker \& Serpe, 1982), it is not a perfect indicator of the importance an individual places on that identity.

The MMRI also emphasizes the individual's perception of what it means to be Black. No a priori definition is provided. The MMRI recognizes that there are individual differences in the qualitative nature of the meaning individuals ascribe to being a member of the Black racial group. Similarly, the MMRI makes no value judgment as to what constitutes a healthy versus an unhealthy racial identity. In order to ask whether a particular identity is either good or bad, one must decide 
upon criteria by which to base one's evaluation. In order to avoid tautology, it is important that the outcome be distinct from the phenomenon being evaluated. In this case, the MMRI represents an assessment of each individual's racial identity (Lazarus \& Folkman, 1984). Certain identities may be associated with more positive outcomes (higher self-esteem, psychological well-being) than others. However, these are empirical questions regarding associations between two separate phenomena. The MMRI does not propose that any identity is, in and of itself, good or bad. It is important that any evaluation of racial identity takes into consideration the ecological environment associated with the identity before evaluating its adaptiveness. It is quite likely that the adaptiveness of particular identities are a function of both the environment and the phenomena used to evaluate adaptiveness.

Finally, the MMRI is primarily concerned with the status of an individual's racial identity as opposed to its development. The MMRI focuses on the significance and the nature of an individual's racial identity at a given point in time in the individual's life as opposed to placing an individual in a particular stage along a particular developmental sequence. In this way, the MMRI differs from developmental models of racial identity such as those proposed by Cross $(1971,1991)$, Phinney (1992), and Milliones (1980). The difference in emphasis does not place the MMRI in direct conflict with these models; instead it provides a potential complement. As noted above, the MMRI allows for the fact that the significance and the meaning that individuals place on race are likely to change across their life span. Developmental models characterize individuals' racial identity according to where they reside on these developmental trajectories, while the MMRI provides a rubric from which to describe the significance and meaning of race at various points along the developmental trajectory. Using the MMRI along with some of the existing developmental models could help validate the assumptions associated with both approaches and provide a more comprehensive understanding of the nature and development of racial identity in African Americans.

\section{Dimensions of the MMRI}

With these assumptions as its foundation, the MMRI proposes four dimensions of racial identity that address both the significance and the qualitative meaning of race in the self-concepts of African Americans. These four dimensions consist of: racial salience, the centrality of the identity, the regard in which the person holds the group associated with the identity, and the ideology associated with the identity. Racial salience and centrality refer to the significance that individuals attach to race in defining themselves; while racial regard and

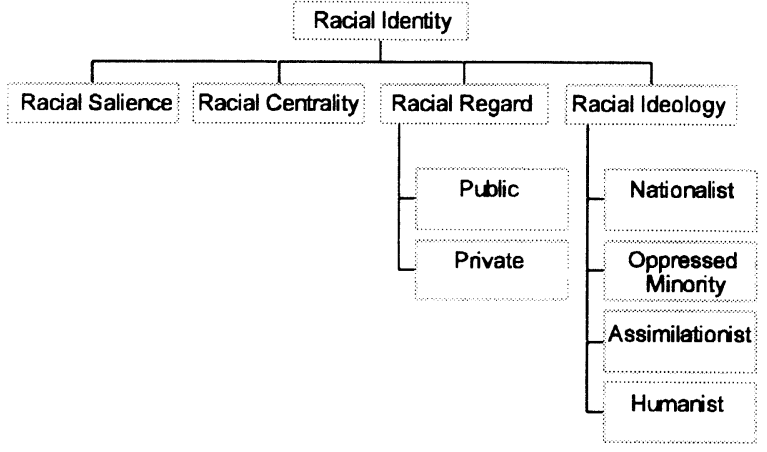

Figure 1. Schematic representation of the multidimensional model of racial identity.

ideology refer to the individuals' perceptions of what it means to be Black (see Figure 1).

Salience. Racial salience refers to the extent to which one's race is a relevant part of one's self-concept at a particular moment or in a particular situation. Thus, racial salience is concerned with the particular event or situation as the unit of analysis. ${ }^{4}$ It is highly sensitive to both the context of the situation and one's proclivity to define oneself in terms of race (McCall \& Simmons, 1978; Rosenberg, 1979; J. C. Turner et al., 1994). Our conceptualization of salience is consistent with Markus and Nurius's (1986) conceptualization of the working self-concept and the notion of spontaneous self-concept (e.g., Cota \& Dion, 1986; McCrae \& Costa, 1988; McGuire et al., 1978; McGuire \& Padawer-Singer, 1976). For instance, Markus and Nurius (1986) suggest that there is a working self-concept that contains a set of self-conceptions that are presently active in thought and memory. They argue that identity within the working self-concept at any moment is determined by the core identity and the immediate social context. Thus, the probability that race may be salient varies across both individuals and situations (Gurin \& Markus, 1988). In general, individual differences in racial salience become more evident in more ambiguous situations as a result of individual differences in the more stable characteristics of racial identity (centrality). For example, being the only African American in an all-

\footnotetext{
${ }^{4}$ The concept of salience is discussed throughout the identity literature (e.g., Cross, 1991; Rosenberg, 1979; Stryker, 1980; Stryker \& Serpe, 1982, 1994; White \& Burke, 1987). In these instances the term has been used to describe the normative importance of an identity to an individual. For instance, Stryker has used the term to describe the probability a particular identity can come into play in a given situation (Stryker, 1980; Stryker \& Serpe, 1982). Such a trans-situational property is more consistent with our conceptualization of centrality. Our conceptualization of salience is more closely akin to that espoused by McCall and Simmons (1978) in which the event is the unit of analysis and salience is considered to be influenced in part by situational cues.
} 
White restaurant may make race salient for one African American, while it may not affect another African American in the same situation. More stable person characteristics, specifically racial centrality, may direct individuals to pay attention to certain cues within the social event and direct attention away from others. On the other hand, some situations are so persuasive that they make race salient for almost all African Americans. That is, it is highly likely that race would be salient for any African American sitting in the middle of a $\mathrm{Ku}$ Klux Klan meeting, instead of a restaurant.

Racial salience is the mediating process between the more stable characteristics of identity and the way individuals construe and behave in specific situations. Studies of in-group bias have consistently shown that making group identities salient (even arbitrary identities) has consequences for the way in which individuals evaluate and behave towards members of both the in-group and out-group (for review, see Messick \& Mackie, 1989). Similarly, the extent to which race is made salient in a particular situation also has an impact on the way that the person construes the situation. In our previous restaurant example, the person for whom race is salient may construe poor service from a White waitress as being the result of possible racism, while the other person is more likely to attribute it to some other factor (such as the waitress is always unfriendly). These construals have very different implications regarding the potential behavior of the two African American customers. Thus, understanding whether race is salient is important in predicting how the two African American customers will respond in a given situation.

Salience is a process variable in that it is a function of both situational cues and person factors (specifically centrality). As such, it is very similar to Lazarus and Folkman's (1984) conceptualization of appraisal in the stress and coping literature. One can not understand salience as being simply the product of the situation and the person. The combination of these two sets of factors results in a third variable that is completely different from the original set of factors. For instance, neither hydrogen nor oxygen alone are water. They only become water when they are combined in specific combination. It is impossible to determine from looking at or tasting water what part is hydrogen and what part is oxygen. As a result of the influence of situational cues, salience is very dynamic and can change from event to event. As a result of person factors, there are also likely to be individual differences in salience within the same event.

Centrality. Racial centrality refers to the extent to which a person normatively defines himself or herself with regard to race. Unlike salience, centrality is, by definition, relatively stable across situations. The unit of analysis for centrality is not a particular event, but instead the individual's normative perceptions of self with respect to race across a number of different situations. Also, implicit in the conceptualization of centrality is a hierarchical ranking of different identities relative to their proximity to the individual's core definition of self (Banaji \& Prentice, 1994; Gurin \& Markus, 1988). For example, some African American women may define themselves more in terms of their gender than their race, while others may use race as the more important self-defining characteristic. The concept of centrality is at the core of many of the existing research models of group, social, racial, and ethnic identity.

Personal construct theory (Kelly, 1955) argues that people define the world and themselves based on different constructs which are idiosyncratic to themselves. The theory argues that certain constructs are more relevant (superordinate) and others are less relevant (subordinate) to how a person views the world or themselves. In personal construct terms, central identities are analogous to superordinate self-constructs and noncentral identities are considered subordinate self-constructs (Ingram, 1989). A critical feature of both the conceptualization of centrality and personal construct theory is its reliance on a phenomenological perspective in determining whether race is central to a person's identity. Cross (1991) discusses some of the limitations of studies which ascribe a certain racial identity to a person based on their membership within a racial classification when attempting to investigate the relationship between identity and some other outcome. Such ascribed identities do not fully incorporate the individual differences in the meaning and relevance of race in the lives of the persons within these racial classifications and as a result obtain inaccurate estimates of the relationship between identity and outcome.

A few researchers from the mainstream perspective have proposed concepts similar to centrality. Luhtanen and Crocker (1992) have incorporated such a concept in their measure of collective self-esteem. This measure includes a 4-item subscale entitled "identity," which measures the person's perceived importance of her or his membership within a specific group. At present, this aspect of their measure has been underutilized and underemphasized. Phinney's (1992) Multigroup Ethnic Identity Measure also includes items tapping a person's feelings of belonging and attachment to one's ethnic group within the Affirmation and Belonging subscale. These concepts are somewhat related to racial centrality. Unfortunately, these racial centrality items are intermingled with items that tap individuals' evaluative attitudes towards their ethnic group. As such, the subscale seems to tap two separate constructs at the same time.

Historically, centrality has played a leading role in the underground approach to African American racial identity. Many of these models are based on the explicit assumption that race is a very central identity in a 
normally functioning African American (Akbar, 1981; Baldwin, 1984; Baldwin, Brown, Rackley, 1990; Kambon, 1992). As such, the extent to which race is a central identity has been viewed as an indicator of the status of individuals' racial identity development as well as their mental health. For example, Baldwin's (1984; also known as Kobi Kambon) model argues that all individuals of African descent are biogenetically predisposed toward a central racial identity when nourished in a nonhostile and affirming environment (Kambon, 1992). Baldwin argues that African personality consists of two core systems. The first is the African Self-Extension Orientation (ASEO), which is biogenetically determined and resides in all people of African descent. The ASEO is hypothesized to be an unconscious core system that warehouses the collective spiritual essence of all African people. The second is a conscious system termed the African Self-Consciousness (ASC), which transforms the ASEO through the individual's life cycle. As a conscious process, ASC is believed to be influenced by both the environment and by biogenetics. Variation in environmental experiences that are culturally affirming lead to individual differences in levels of ASC, such that individuals in a more culturally affirming environment are likely to have higher levels of ASC (Baldwin, 1984; Baldwin, Brown, \& Rackley, 1990; Kambon, 1992).

Although some theorists have assumed that race is most central, empirical research suggests that race is not always a central aspect of many African Americans' self-concept (Ingram, 1989; Phinney \& Alipuria, 1990). Ingram (1989) used the Role Construct Repertory Grid to assess the meaningfulness of various self-constructs in a predominantly female (72\%) sample of African American college students. She found that although participants rated race as a meaningful self-construct, gender was rated as the most meaningful construct. Phinney and Alipuria (1990) asked participants to rate five identity domains (occupation, politics, religion, gender role, and ethnicity) on a 4-point scale ranging from 1 (not at all important) to 4 (very important). Their results revealed that ethnic identity tied for third place with religious identity among the African American participants in their sample. In fact, some researchers have even begun to suggest that having a less central racial identity may be more adaptive for African Americans (Penn, Gaines, \& Phillips, 1993). Unfortunately, there is a dearth of studies that have empirically investigated the relation between racial centrality in African Americans and mental health status (Sellers, 1993). Those few studies that have attempted to assess such a relation have been limited by measures of centrality that are confounded with other aspects of racial identity (e.g., Parham \& Helms, 1985). Thus, it is imperative that the significance of race in individuals' self-concepts be conceptualized and operationalized distinctly from other aspects of racial identity.
Whereas the salience and centrality dimensions of the MMRI address the question of the significance of race in individuals' lives, the regard and ideology dimensions address the question of the meaning that individuals attribute to being Black. As such, these two dimensions attempt to capture some of the texture and richness associated with African American racial identity that flows from the heterogeneity within the Black experience.

Regard. Feelings of positivity and negativity towards being Black has been a consistent theme in the research literature on African Americans. As Cross (1991) points out, much of the early work on African American racial identity viewed preference for one's own group as instrumental in the conceptualization of racial identity (e.g., Clark \& Clark, 1947; E. L. Horowitz, 1936; R. Horowitz, 1939). African American children's preference for White stimuli (such as dolls) was seen as evidence of African American adults' devaluation of their race which in turn was explained away as the natural consequence of African Americans internalizing the broader society's negative view of them (Cross, 1991). Later, researchers from the underground perspective also placed a great deal of emphasis on individuals' evaluations of Blacks in their models of African American racial identity (e.g., Baldwin, 1984). They tended to conceptualize positive feelings towards Blacks as being an essential component of a healthy racial identity. In any event, individuals' evaluations of Blacks as a group have historically been conceptualized as an important component of African American racial identity.

We attempt to address this theme of group evaluation within the MMRI via our conceptualization of the regard dimension. Racial regard refers to a person's affective and evaluative judgment of her or his race in terms of positive-negative valence. In other words, it is the extent to which the individual feels positively about his or her race. This conceptualization of racial regard is based heavily on Crocker and her colleagues' work on collective self-esteem (Crocker \& Luhtanen, 1990; Crocker, Luhtanen, Blaine, \& Broadnax, 1994; Crocker \& Major, 1989; Luhtanen \& Crocker, 1992). Like their model of collective self-esteem, our regard dimension consists of both a private and a public component. Private regard is defined as the extent to which individuals feel positively or negatively towards African Americans as well as how positively or negatively they feel about being an African American. This component of regard is also consistent with the concept of psychological closeness and racial pride in other models (e.g., Demo \& Hughes, 1990; Hughes \& Demo, 1989).

Public regard is defined as the extent to which individuals feel that others view African Americans positively or negatively. It is the individual's assess- 
ments of how his group is viewed (or valued) by the broader society. Researchers from both the mainstream and underground perspectives have argued that the concept of public regard plays an important part in the way in which African Americans identify with their own group. The mainstream approach has generally argued that the devaluation of African Americans by the broader society should have a deleterious influence on individuals' evaluation of their own group ( $R$. Horowitz, 1939; Kardiner \& Ovesey, 1951; Lewin, 1936, 1941; Luhtanen \& Crocker, 1992; Mead, 1934; Stryker, 1980; C. L. White \& Burke, 1987). As such, much of the mainstream research has implicitly suggested that having a public regard that recognizes the broader society's devaluing of ones group (stigmatizing) should most likely lead to a more negative evaluation of that group (private regard).

In contrast, much of the research from the underground approach has argued that understanding and acknowledging the oppression that African Americans continue to face is an important step in the development of a healthy African American racial identity (e.g., Baldwin \& Bell, 1985; Parham \& Helms, 1981; Terrell $\&$ Terrell, 1981). As such, the underground perspective tends to place much less emphasis on the broader society's ability to imprint its attitudes regarding African Americans on African Americans. The underground perspective has been quicker to recognize the cultural factors-such as the African American family, church, and community - that may moderate these messages from the mainstream (e.g., Broman, Jackson, \& Neighbors, 1989; McAdoo, 1985). In fact, many of the models have argued that understanding that the broader society devalues African Americans (as a result of racism) helps to keep African Americans from internalizing those negative messages regarding their worth.

Unfortunately, research testing these opposing predictions is scarce because researchers have failed to operationally define the concepts of private and public regard independently. In one of the only studies to measure both private and public regard independently, Crocker et al. (1994) used a race-specific version of their Collective Self-Esteem Scale (CSES) to assess the relation between the different components of this scale for a sample of African American, White, and Asian American college students. For the African American students, private race-specific CSES (private regard) was not correlated with public race-specific CSES (public regard). Interestingly, the public and private race-specific CSES scores were significantly positively correlated for both White and Asian American students. Although Crocker and her associates' (Crocker et al., 1994) findings of no significant relation between private and public regard does not support either the mainstream or the underground perspectives view, the differences in the correlations between the African Americans and the other two groups reinforce the view that it is important to study African American identity within its own cultural and historical context.

Ideology. The fourth dimension of the MMRI, ideology, is composed of the individual's beliefs, opinions, and attitudes with respect to the way she or he feels that the members of the race should act. This dimension represents the person's philosophy about the ways in which African Americans should live and interact with society. Based on our reading of the research literature and exposure to African American culture, we have delineated four ideological philosophies which seem to be prevalent: (a) a nationalist philosophy, (b) an oppressed minority philosophy, (c) an assimilation philosophy, and (d) a humanist philosophy. These four ideologies are manifested across four areas of functioning consisting of individuals' attitudes with respect to: (a) political/economic development, (b) cultural/social activities, (c) intergroup relations, and (d) perceptions of the dominant group. Although a person can be categorized as possessing a particular ideology, it is likely that most people hold a variety of philosophies that often vary across areas of functioning. For example, a person could believe that African Americans should primarily patronize African American owned businesses (nationalist) and at the same time feel that African Americans should integrate White institutions (assimilation).

The nationalist ideology stresses the uniqueness of being Black. As such, the nationalist person views the African American experience as being different from that of any other group. A nationalist ideology posits that African Americans should be in control of their own destiny with minimal input from other groups. Thus, with respect to issues of social change, a person with a nationalistic perspective is more likely to participate in African American organizations. A nationalist ideology can evolve as a mechanism of resistance to the marginalized status that African Americans have in this society (Parham, 1989). A nationalist ideology can also grow out of a deep appreciation and awareness of the culture and accomplishments of African Americans. In many instances, individuals' nationalist philosophies are developed as a result of both experiences. A nationalist ideology is also associated with a preference for African American (or African) social environments. Some of the underground models have viewed a nationalist ideology as being the optimal Black identity (Baldwin, 1984), while others (Cross, 1991) suggest that ultranationalistic attitudes may be characteristic of a racial identity which has not fully developed. As noted earlier, the MMRI places no inherent value in the extent to which one endorses a nationalist ideology.

The oppressed minority ideology emphasizes the similarities between the oppression that African Americans face and that of other groups. Like the nationalist 
ideology, individuals who espouse this philosophy are acutely aware of the oppression that continues to confront African Americans. However, the oppressed minority ideology sees a link between the oppression that African Americans face and that of other minority groups. The model allows these minority groups to differ according to the individual. For some individuals, other oppressed groups with whom they identify as minority may consist of women, gay men, and lesbians; others may define minorities as only consisting of ethnic groups of color. In any case, an individual endorsing the oppressed minority ideology is more likely to view coalition building as the most appropriate strategy for social change. From an intellectual standpoint, individuals with an oppressed minority ideology are often interested in the nature of oppression. From a cultural perspective, these individuals are as interested in the culture of other minority groups as they are their own.

The assimilationist ideology is characterized by an emphasis on the similarities between African Americans and the rest of American society. A person with an assimilationist ideology acknowledges his or her status as an American and attempts to enter, as much as possible, into the mainstream. An assimilationist ideology does not necessarily imply a de-emphasis in the importance of being African American, nor does it necessarily imply a lack of recognition of racism in America. A person with an assimilationist ideology can be an activist for social change; however, he or she is likely to feel that African Americans need to work within the system to change it. Interpersonally, persons with an assimilation ideology are more likely to believe it to be important to interact socially with Whites. The underground approach has often viewed an assimilationist ideology as being symptomatic of the earliest stages of identity development (Cross, 1971; Parham \& Helms, 1985) and even pathological (Kambon, 1992). Our model makes no such assumption. An assimilation ideology may represent for the individual a means to an end or it may represent an end in itself.

Finally, the humanist ideology emphasizes the similarities among all humans. Persons with a humanist viewpoint do not think in terms of race, gender, class, or other distinguishing characteristics. They are likely to view everyone as belonging to the same race-the human race. A humanist ideology is often concerned more with "larger" issues facing the human race (such as the environment, peace, and hunger). Oppression is seen in terms of "man's inhumanity towards man." Thus, humanists are likely to emphasize the moral detriments of oppression for the oppressor as well as the physical and psychological consequences it has for the oppressed. Individuals with a humanist ideology see race as being of only minor importance with respect to the way that they lead their lives (low centrality) and view the world. As a result, they are more likely to emphasize the characteristics of the individual person, regardless of race. Penn et al. (1993) have argued that an ideology that de-emphasizes race is representative of the highest level of identity development. Interestingly, Cross's revised model suggests that a humanist ideology may be consistent with both the earliest (preencounter) and the latest (internalization) stages of identity development (Cross, 1991).

Racial identity is a complex component of the African American self-concept. The MMRI does not consider any of the four dimensions to be synonymous with racial identity, just as the individual's arm is not synonymous with his or her whole body. The dimensions simply represent different ways in which racial identity is manifested. It should be noted that different dimensions of racial identity are related to different behavioral and adaptational outcomes. Researchers should choose the dimension of racial identity that they study based on the goals of their research. Relatedly, racial identity should not be seen as a panacea. There are many behavioral and adaptational outcomes that are not related to racial identity.

\section{Mechanism by Which Racial Identity Influences Behavior}

The processes by which individuals' beliefs regarding the meaning and significance of race can influence the way in which they appraise and behave in specific events has not been delineated in the current literature on racial identity. The MMRI attempts to address this oversight through the conceptualization of salience and its relation to constructs in the construct accessibility literature. Numerous studies have demonstrated that the construct that is most accessible to the person during a particular event is the construct most likely to be used in judgments of behavior or impression formation in that particular event (Bargh, Bond, Lombardi, \& Tota, 1986; Bargh, Lombardi, \& Higgins, 1988; Bargh \& Pietromonaco, 1982; Bargh \& Pratto, 1986; Bargh \& Thein, 1985; Higgins, King, \& Mavin, 1982; Higgins, Rholes, \& Jones, 1977). Higgins $(1989,1990)$ delineates two forms of accessibility in describing the ways in which a construct may become accessible in a particular event. A temporarily accessible construct becomes accessible as a result of recent contextual or situational factors, while a chronically accessible construct is one that has a high probability of becoming accessible in any situation. Chronically accessible constructs develop out of each person's unique life history of social encounters. They develop from frequent experience with a specific domain of social behavior related to the construct. A construct can be both temporarily accessible and chronically accessible in a situation in which both the situational cues and the person's proclivity towards a particular construct point to the same construct. 
The salience and centrality dimensions of the MMRI are consistent with the conceptualization of construct accessibility. Individuals' regard and ideology beliefs represent constructs about the meaning of being Black. Salience and centrality represent the accessibility of the regard and ideology constructs. Salience is consistent with the concept of accessibility in a particular event. Race may become salient (accessible) in a particular event as a function of situational factors, making it similar to Higgin's (1989) notion of temporary accessibility. However, race may also be salient in a particular event as a result of an individual's proclivity for race to become salient (centrality or chronic accessibility). In general, both the situational cues and the personal proclivity interact to influence the salience or accessibility of race.

Other research has shown that when certain constructs are made accessible the content of these constructs are better predictors of individuals behaviors in specific situations than when the constructs are not accessible (see Fazio, 1986, 1990; Fazio \& Zanna, 1981, for reviews). Fazio's (1990) review of the literature notes the ubiquity of the impact of accessibility of a construct on the person's subsequent behavior in a situation. Although Fazio acknowledges that an attitude can be activated because of situational, or more inherent, personality factors, he suggests that how the attitude is activated is less important than the fact that the attitude is activated or becomes accessible to the individual. The more accessible an individual's attitude toward an object, the more likely it is that the individual will behave in a way that is consistent with the attitude. The activation of the attitude encourages individuals to appraise the situation in ways that are consistent with the attitude. Interestingly, the majority of the work on the moderating effect of attitude accessibility on the relation between attitudes and behavior focuses primarily on attitudes toward objects or other people, not attitudes about the self. However, Markus's (1983; Markus \& Sentis, 1982) conceptualization of selfknowledge suggests that the moderating effect of acces- sibility can be applied towards attitudes individuals have about the self. That is, information individuals have about the self influences behavior most when this information is most relevant to the individual's selfconcept.

Individuals' regard and ideology beliefs are attitudes about the meaning of being Black and as such they should influence individuals' behavior during specific events in a manner that is consistent with the attitudes that have been traditionally measured in the research literature on attitude accessibility. Specifically, regard and ideology beliefs should have a greater influence on individuals' behavior at the level of the event when race is more salient than when it is less salient. This suggests a process by which the content of an individuals racial identity (ideology and regard beliefs) may influence behavior at the level of the situation (see Figure 2). Situational cues and centrality interact to determine the extent to which race is made salient during a particular event. The level of race salience in a particular event then moderates the extent to which the individual's ideology and regard beliefs influence their interpretation of the event as well as their subsequent behavior within the event.

The centrality of a particular role/identity has been found to be associated with the performance of behaviors that are indicative of that particular role/identity (e.g., Stryker \& Serpe, 1982). However, this research has focused primarily on roles/identities for which there is a consensus within society regarding the meaning of the role/identity. As noted above, the historical experiences of African Americans have led to a great deal of variability in the qualitative meaning that African Americans attribute to being Black. As a result, individuals may vary in the way that they behave in a particular situation as a function of differences in the level at which race is salient and/or as a function of differences in the qualitative meaning that they ascribe to being Black (ideology and regard). Thus, two individuals with similar ideology and regard beliefs may behave differently in the same situation because one is

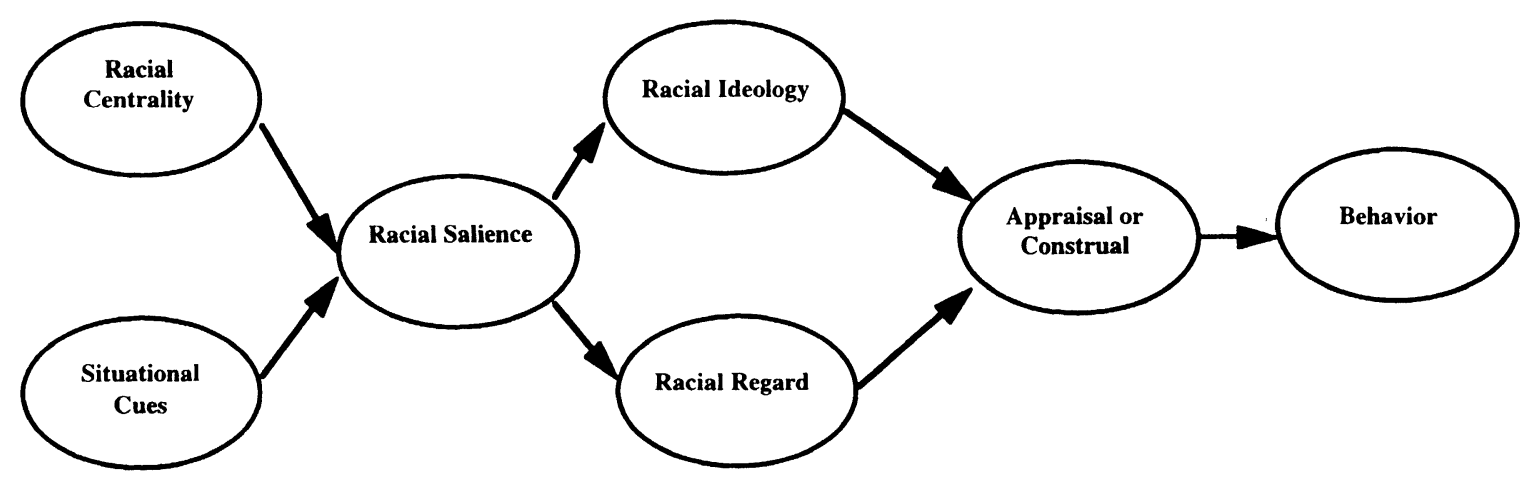

Figure 2. The process by which racial identity influences behavior at the level of the event. 
interpreting the situation through the lens of his racial identity because it has been made salient, while the other person may be interpreting the situation through some other identity lens because race is not salient to them in this situation. Similarly, two individuals in the same situation for whom race is equally salient may also behave differently because the two individuals may differ with respect to the content of their racial identity schema (ideology and regard beliefs).

The conceptualization of the salience dimension is critical to the delineation of a process by which the stable dimensions of racial ideology may influence behavior. Salience provides an important bridge between the molar level of analysis and the molecular level of analysis. The conceptualization of salience allows for the delineation of a process that accounts for the heterogeneity in individuals' responses to particular events, while at the same time provides specific predictions about an individual's behavior when information is known about the situational cues regarding race, as well as the significance and meaning that the individual attributes to being Black.

While salience is critical to our understanding of the relation between the content of the individual's racial identity and his or her behavior at the level of a particular event, centrality is also critical to our understanding of the relation between racial identity and trans-situational behavior or phenomena. The term trans-situational phenomena refers to behavior and attitudes that are a result of individuals' actions and thoughts across a number of situations. Examples of trans-situational phenomena include things such as grade point average (GPA), global self-esteem, trait anxiety, and life satisfaction. Trans-situational phenomena are more likely to be influenced by racial regard and ideology attitudes when an individual's racial identity plays an important role in how he or she defines himself or herself normatively across events. Individuals may hold attitudes about any group in which they belong, but those attitudes are only going to be self-diagnostic if the identity itself is self-relevant. For instance, an individual may have feelings about his social security number. He may be able to tell you which numbers he likes and which ones he dislikes. However, knowing that information tells us nothing about the way that the individual feels unless the individual defines himself or herself in terms of his or her social security number. As noted previously, African Americans differ in the level of significance race plays in their self-concept. That individual difference in the significance of race influences the extent to which the qualitative meaning that they ascribe to being Black impacts their behavior at the molar level.

Our research program has found consistent evidence that an individual's level of centrality moderates the relation between his or her beliefs regarding the meaning of race (regard and ideology) and trans-situational behavior or phenomena. In a study examining the rela- tions among centrality, private regard, and personal self-esteem, we found a significant moderating effect for centrality (Rowley et al., in press). For individuals who were low in racial centrality, there was no relation between how positively they felt about Black people (private regard) and their personal self-esteem. For individuals who were high in racial centrality, however, a positive relation was found between private regard and personal self-esteem. Similarly, centrality moderated the relation between racial ideology and college GPA (Sellers, Chavous, \& Cooke, in press). Once again, for individuals for whom race was not a central identity, there was no relation between their racial ideology and GPA. For individuals for whom race was central, however, there were significant relations between three of the ideology subdimensions (i.e., minority, nationalist, and assimilation) and GPA. Thus, although individuals may have beliefs regarding what it means to be Black, these beliefs are going to be diagnostic only when the individual sees being Black as an important part of who they are.

\section{Operationalization of the Multidimensional Model of Racial Identity}

In order to operationalize the MMRI, we developed the Multidimensional Inventory of Black Identity (MIBI). In developing the MIBI, we adapted items from previous identity scales as well as developed items on our own. The MIBI is comprised of 3 scales that measure the centrality, ideology, and regard dimensions. The Ideology Scale also consists of 4 subscales (Nationalist, Assimilation, Minority, and Humanist), and the Regard Scale consists of 2 subscales (Private Regard and Public Regard). The sensitivity of Salience to context cues and its dynamic nature makes its operationalization via a questionnaire instrument problematic. Racial salience is best measured using experimental and quasi-experimental methods in which the effects of the social context are either manipulated or measured (Shelton \& Sellers, 1996). Thus, the MMRI is amenable to a multimethod approach to studying racial identity.

Preliminary analyses suggest that the MIBI is a valid and reliable measure of the MMRI (Sellers, Rowley, Chavous, Shelton, \& Smith, 1997). A sample of 474 African American college students from two universities (one predominately White American and one predominately African American) was used to evaluate the reliability and validity of the MIBI. Using factor analyses, we found evidence in strong support of a Centrality Scale and four ideology subscales that was consistent with the MMRI. The Centrality and Ideology Scales yielded acceptable alpha coefficients ( $\alpha$ s range from .70 to .79) for the examination of both predictive and construct validation (Nunnally \& Bernstein, 1994). The evidence for the internal validity of the Private Regard 
subscale was modest $(\alpha=.60)$ and the Public Regard subscale was weak $(\alpha=.20)$. Recently, we revised a number of items to the Regard Scale that has resulted in two scales that are both internally consistent (Private Regard $\alpha=$.78; Public Regard $\alpha=.78$ ). Factor analysis with a sample of African American college students found the revised Regard subscales to be distinguishable from each other and the Centrality Scale. The revised Regard subscales were also highly correlated with the previous Regard subscales (Public Regard $r=$ .87 , Private Regard $r=.87$ ).

We have also found evidence of the predictive validity of the MIBI (Sellers, Rowley, et al., 1997). Subscales of the MIBI demonstrated significant relations with the amount of contact individuals reported with Blacks and with Whites. Specifically, individuals with a Black best friend scored higher on the Centrality and Nationalist scales and lower on the Assimilation, Humanist, and Minority ideology scales. Centrality, Private Regard, and Nationalist scores were positively associated with contact with Blacks, while Centrality and Nationalist scores were negatively associated with contact with Whites. (See the Appendix for items that comprise the MIBI.)

Shelton and Sellers (1996) conducted a study in which gender and racial identity were manipulated within a sample of African American college women to investigate the influence of situational factors on racial identity salience and the stable dimensions of the MMRI. The identities were manipulated by altering the content of a video recording as well as the racial and gender composition of the group with which the student viewed the recording. Our conceptualization of salience suggests that it is a function of both situational factors and individuals' level of centrality. Shelton and Sellers found strong evidence that centrality influenced identity salience in race- and gender-ambiguous conditions. There was also moderate evidence that the situation manipulations influenced individuals' racial identity salience. Finally, individuals' scores on the MIBI taken 8 weeks prior to their participation in the study did not change as a function of the situation manipulations (including the race-salient condition). These findings suggest that the MMRI has properties that are both situationally dynamic and cross-situationally stable.

These preliminary findings are promising. They suggest that the MMRI can be operationalized in a valid and reliable manner. However, more research is needed before the full impact of the MMRI can be assessed.

\section{Potential Contributions of the MMRI}

A potential strength of the MMRI is that it attempts to combine the strengths of both the mainstream and underground approaches to studying African American racial identity. In essence, the MMRI provides an integrated framework in which to investigate the structure and properties associated with the functioning of African American racial identity within its own unique historical and cultural experience. Despite our attempt to develop an integrative framework, it is also important to demonstrate how the MMRI makes contributions above the current models of ethnic/racial identity. In comparing the MMRI with two of the most popular mainstream models, Crocker's Collective Self-Esteem model and Phinney's Model of Ethnic Identity, a major contribution of the MMRI is its ability to provide a more textured view of the meaning of being Black as a result of its being developed within the context of the unique experiences associated with African American history. Neither the Collective Self-Esteem model nor Phinney's Model of Ethnic Identity does justice to the rich heterogeneity in the meaning that African Americans attribute to being Black. This limitation can be illustrated in the models' inability to discriminate between the identity beliefs of two such diverse African Americans as Martin Luther King and Malcolm X.

An examination of the racial identity beliefs espoused by Martin and Malcolm in the context of Luhtanen and Crocker's (1992) Collective Self-Esteem Scale (CSES) demonstrates its limitations. Both Martin and Malcolm viewed race as being central to their self-concept; thus they would have scored high on the identity subscale of the CSES. Both individuals viewed other groups as holding negative views about Blacks, thus scoring low on the Public Collective Self-Esteem subscale of the CSES. Both held positive beliefs about Blacks (scoring high on the Private Collective Self-Esteem subscale of the CSES), and both Martin and Malcolm felt positively about being Black (high score on the Membership subscale of the CSES). Despite the fact that the Collective Self-Esteem model has components that are similar to two dimensions of the MMRI (centrality and regard), the model does not capture diversity in the way in which they defined what it means to be Black. ${ }^{5}$

Similarly, if one examines the racial identity beliefs espoused by Martin and Malcolm using Phinney's (1992) Multigroup Ethnic Identity Measure (MEIM), we also see some of the limitations of the model in describing the content of these individuals' racial identity. Both Martin and Malcolm searched and committed to a racial identity (high score on the identity Achievement subscale of the MEIM). Both individuals engaged in a number of activities and organizations that involved primarily African Americans (high score on the Ethnic Behaviors subscale of the MEIM). Both Martin and Malcolm had a strong attachment and pride in being

\footnotetext{
${ }^{5}$ Our conceptualization of the Regard dimension is based heavily on Crocker and Luhtanen's (1990) conceptualization of Collective Self-Esteem. However, our conceptualization of centrality was derived from the work of a number of identity models found in both the mainstream and the underground literatures.
} 
Black, thus scoring high on the Affirmation and Belonging subscale of the MEIM. One aspect of the MEIM in which the two may have differed may have been on the Self-Identification tasks. But this difference would have depended on the point in Martin's adult life at which he would have been surveyed. At the time of his death, Martin is likely to have used the term Black, just as Malcolm used when he died three years earlier. Nonetheless it is clear that the MEIM also fails to capture something important about the racial or ethnic identities of these individuals.

It should be noted that neither Crocker nor Phinney make claims that their models address the unique cultural experiences associated with a particular group. Instead, both researchers have focused on the similarities associated with group identification. Thus, much of their research has looked at this phenomenon across groups (e.g., Crocker et al., 1994; Phinney, 1989; Phinney \& Alipuria, 1990). It is also interesting to note that Crocker and Phinney developed their models based on previous work on aspects of the individual-personal self-esteem (Crocker \& Luhtanen, 1990) and ego identity development (Phinney, 1989), respectively. The genesis of these models may also account for the de-emphasis on the rich heterogeneity within identities in favor of a more general view of identity. Both the self-esteem literature and Erickson's (1968) ego identity literature has focused primarily on stigma to the exclusion of culture in its investigation of African Americans.

On the other hand, an examination of Martin and Malcolm in the context of the MMRI allows for both the similarities and the important differences in the way in which they viewed being African Americans. As noted previously, both Martin and Malcolm were high race central. Both individuals also were high in private regard and felt that others had negative beliefs about Blacks (low public regard). A major difference between the two individuals' self-definitions about what it means to Black is captured in the ideology dimension. In general, Martin's political and economic beliefs were more assimilationist according to the MMRI, while Malcolm's political and economic beliefs were more nationalist. An even more textured view of the two using the MMRI would suggest that Malcolm's ideology regarding social interaction went from more nationalist views as a member of the Nation of Islam to more humanist after his trip to Mecca. Meanwhile, Martin's ideology regarding social interaction seems to have remained somewhat humanist throughout his adult life. An analysis of one's ideology beliefs becomes more complex and detailed as one begins to take more life domains into consideration. Although other aspects of African American racial identity are important predictors of different phenomena, it is clear that, without a dimension like ideology, one's view of individual African American's racial identity would be overly simplistic and incomplete.
The lack of texture in the identity profiles of African Americans also has implications for one's ability to make predictions about behavior. Without a more complex view of individuals' beliefs about the meaning of race, we are limited in the types of behavioral predictions we are able to make. For instance, much of the research on in-group bias has focused on the way in which individuals treat members of their group as well as the out-group. The examination of this treatment is always based on a positive-negative valence. This research has been very important in our understanding of group processes associated with stigma, favoritism, and discrimination. However, such approaches are severely limited in their applicability to our understanding of African American racial identity because they do not take into consideration the meaning that individuals attribute to their group membership. (In the minimal group paradigm, the goal is to develop groups for which individuals have no rational reasons to attach meaning.) Unless one is willing to consider that African American racial identity is composed simply of a stigmatized status and a membership in a salient group, then we are missing something important about racial identity. Conceptualizing African American racial identity in such a way greatly limits our ability to capture the richness of the experience associated with the identity as well as our ability to make predictions about any but the most circumscribed behaviors. For instance, such a conceptualization makes it impossible to explain why one African American may feel most comfortable at an opera, another may feel more comfortable at a rap concert, and a third may feel most comfortable at a salsa party, while still another African American may feel equally comfortable in all three situations.

In providing a framework for examining both the significance and meaning of being Black, the MMRI has the potential to make important contributions to the underground approach. At present, much of the research from the underground perspective summarizes African American racial identity along a single dimension (e.g., Baldwin, 1984). In so doing, many of the models have failed to capture the diversity of experience in the African American community or have pathologized those experiences that do not fit with the author's conceptualization of racial identity. The MMRI provides three different dimensions that can be used to develop profiles of individuals' racial identity. Such profiles may be compatible with other underground models that focus on the development of racial identity (Cross, 1991; Milliones, 1980). At present, it is an open question whether certain identity profiles are associated with different stages of identity development. The MMRI also expands the underground approach's current descriptive focus by providing a framework for documenting the role of racial identity within the self-concept. As such, researchers from both approaches can begin to examine how different group 
identities within an individual's self-concept interact and affect his or her experiences. Too often racial identity is studied within a vacuum. Racial identity is likely to interact with other identities within the selfconcept in such a way as to change its meaning for the person. For instance, it is quite possible that African American women's racial ideology may vary according to the ideologies associated with their gender identity. There may even be gender differences in racial ideology as a result of differences in the meaning of gender for African American men and women. These are testable research questions within the framework of the MMRI.

Another contribution of the MMRI is in the way it addresses what constitutes the optimal racial identity. The underground perspective has argued that the individual's perceptions with regard to the meaning of being African American are a function of both the person's unique culture and his or her experiences as a member of an oppressed group (e.g., Akbar, 1984; Cross, 1991; Kambon, 1992; Milliones, 1980; Nobles, 1991). As a result, underground models have tended to employ methodologies that are sensitive to the individual differences in African American identity. However, in describing the diversity of the meaning of being African American, most theorists and researchers have attempted to define what constitutes the optimum African American racial identity. Unfortunately, many of these definitions of the optimum identity are based on untested and/or untestable assumptions and criteria (Sellers, 1993). In some instances, the criteria used to determine the optimum identity are so confounded with the measures of identity themselves that the model itself becomes hopelessly unfalsifiable (e.g., Kambon, 1992).

In our conceptualization of racial identity, we do not propose any hierarchy with respect to the inherent value of any particular ideology. Any evaluation of the functionality of a particular ideology differs according to which criterion is used to define functionality. For example, a person who values the survival of African American culture as a unique and separate way of life may be more likely to see a nationalist ideology as being optimal. On the other hand, a person who values the acceptance of African Americans by the broader American society may view an assimilationist ideology as being optimal. Even if consensus existed on a criterion (such as psychological well-being) to be used to determine an optimal ideology, it is likely that such a definition would have to be environmentally specific. Different environments are likely to be more hospitable for different racial ideologies which may, in turn, contribute to different levels of well-being. For instance, a nationalist ideology is probably more likely to be associated with positive well-being in an all-African American environment than in an all-White environment. In any event, our conceptualization of ideology allows researchers to test such a hypothesis.
The MMRI also has the potential to contribute to the extensive literature on stereotyping. It has been noted that the stereotype literature has tended to focus on those who hold stereotypes with relatively little attention being paid to the effects of such stereotypes on the stigmatized group (Devine, Evett, \& Vasquez-Suson, 1996). Recently, Steele and his colleagues have proposed a model of stereotype threat which suggests that members of a stigmatized group are vulnerable to performance deficits in tasks for which their group is stereotyped as being inferior (Steele, 1997; Steele \& Aronson, 1995). Steele and Aronson (1995) have reported evidence that African American college students performed poorer on a reading comprehension task when their race was made salient to them. They suggest that it does not matter whether the person believes the stereotype; what is important is that the person knows that the stereotype exists. In their description of stereotype threat, Steele and Aronson do not discuss whether all African Americans would be susceptible or what factors might lead to individual differences to vulnerability to the effect. The MMRI suggests that the meaning and significance that the individual places on race may moderate the stereotype threat effect. In particular, individuals who are more race central may need fewer race cues in the environment for race to become more salient during a particular task. As a result, they may be more susceptible to such an effect. However, this effect may also be moderated by the extent to which the individual believes that other groups hold those negative stereotypes about the group (public regard). A person who does not believe that others hold such stereotypes may be less vulnerable to the effect. Finally, it is still an open question as to whether a person's own beliefs about whether African Americans are less capable on a task will influence the stereotype threat effect. In sum, the MMRI has the potential to further explicate person characteristics which may result in greater differentiation in the impact of stereotype threat on the performance of African Americans.

Perhaps the most important contribution of the MMRI is that it delineates a process by which racial identity may influence behavior at the level of the event through its conceptualization of racial identity. This issue is one that has been overlooked by both the mainstream and the underground literatures. Previously racial identity has been linked primarily to trans-situational phenomena (e.g., self-esteem, GPA). While such studies have provided useful information regarding what outcomes racial identity is related to, these studies have been unable to delineate how racial identity is related to these outcomes. Because trans-situational phenomena are comprised of a number of individual events, one must be able to examine racial identity at the level of the specific situation. Without a process variable such as salience, one is forced to assume that all individuals in the situation will have the same level 
of race salience in the situation. Such an assumption is only tenable during events where the situational cues are so strong that they overpower any individual differences in centrality (e.g., Klu Klux Klan meeting). However, the vast majority of events are ones in which there is some ambiguity with respect to the situational cues that are present. In such situations, we expect individual differences in levels of race salience. The concept of salience allows us to account for that individual difference in our assessment of behavior. As a result, we are able to make more precise predictions and account for a greater amount of the variance in our measurement models of the relation between racial identity and behavior at the level of the event.

\section{Racial Identity Versus Identity of Racial Groups}

Recently, a number of mainstream researchers also have begun to explore the content of the identities of members of ethnic minority groups (Deaux, 1993; Ethier \& Deaux, 1990, 1994; Gurin, Hurtado, \& Peng, 1994; Oyserman, Gant, \& Ager, 1995). This research suggests that ethnic minorities have rich, sophisticated notions of self that are not homogenous. Identity in ethnic minority members is influenced by their social context (Deaux, 1993; Oyserman et al., 1995), as well as other social structures such as nativity (Gurin et al., 1994), to produce unique conceptualizations of the self. For instance, Gurin and her colleagues examined the differences in the way in which a sample of Mexicano and a sample of Chicano respondents described themselves as individuals. They define Mexicanos as Spanish-dominant persons born in Mexico and Chicanos as English-dominant persons born in the United States. The respondents chose all the cards that described them from a set of 32 cards with labels covering a variety of ethnic, familial, cultural, class, and color terms. Using confirmatory factor analysis, Gurin et al. (1994) found that Chicanos demonstrated more differentiated identities (greater number of factors) than the Mexicanos. The content of the Chicano identities consisted of such factors as Farmworker, Working Class, U.S./Middle Class, Binational, Latino, Political Raza, and Family, while the content of the Mexicanos consisted of such factors as Working Class, Middle Class, Binational, Panraza, and Family Cultural Identification.

However, there is an important distinction between this research and the underground approach to understanding racial identity in African Americans. The former research has focused on the content of identities of individuals who are members of particular ethnic and racial groups. Findings from these studies provide information about the way that individuals in particular ethnic and racial groups construct their own personal self-concepts with their race and/or ethnicity as a backdrop. As such, this approach takes into consideration not only membership in their ethnic group, but other group and personal identities that are central to the way that each individual views him or herself (e.g., class, family). Thus, the focus of this work is on the "self-concepts" of members of particular ethnic and racial groups.

In contrast, researchers within the underground approach have tended to focus more on the meaning of being a member of a particular group-Blacks. The individual's identification with his or her membership in the Black group is the only group identity that is relevant. In most instances, the researchers provide an a priori definition of what it means to be Black and the individual's level of racial identity is assessed according to that definition. Other group and personal identities that the individual may possess are not seen as particularly relevant. This is, in part, because many of the underground approaches to Black identity implicitly assert that a strong identification with race is a necessary part of a healthy Black identity and that the emphasis of another group identity over one's racial group is unhealthy (Baldwin, 1984). Thus, the underground approach to studying racial identity is concerned solely with that aspect of African Americans' self-concept that is associated with their race.

The conceptualization of the MMRI is more consistent with the tradition of the underground approach. The MMRI is concerned with African Americans' attitudes and beliefs associated with their membership in the Black racial group. The MMRI does not address directly the content of African Americans' self-concept outside of the significance and meaning the individual attaches to being Black. This does not mean that the MMRI is incompatible with a more multidetermined view of the African American self-concept. On the contrary, we believe that African Americans' beliefs about what it means to be Black can play a significant role in shaping their self-concepts if they view race as a defining characteristic (Rowley et al., in press). Whereas research such as that produced by Gurin and her colleagues (Gurin et al., 1994) take a macro view of the various identity components found in the self-concepts of members of ethnic groups, the MMRI represents a micro view of a particular identity component within the self-concept of African Americans. Thus, research on the content of the self-concept of African Americans can provide breadth to our understanding of what identity components play a role in the self-concepts of African Americans, while research from the underground perspective (including the MMRI) can provide important information about the depth of a particular identity dimension. Both are needed for a comprehensive, textured, and layered understanding of the self-concepts of African Americans. 


\section{The Generalizability of the MMRI to Other Groups}

The extent to which the MMRI can serve as a metaframework for examining other group identities (such as ethnicity and gender) is open to debate. Because the MMRI integrates ideas from the mainstream approach, certain aspects of the model may be applicable to other group identities. In particular, the structure and the processes of group identity may be similar across groups. For example, much of the mainstream literature has reported evidence of the existence of identity salience and centrality for identities other than African American racial identity (e.g., Cota \& Dion, 1986; Luhtanen \& Crocker, 1992; Markus \& Nurius, 1986; McCrae \& Costa, 1988; McGuire et al., 1978). Salience and centrality appear to be general cognitive processes that are not confined to any one identity. Thus, in a fairly gender-ambiguous situation, we would predict that gender is likely to be more salient for a woman for whom gender is a highly central aspect of her identity than for a woman for whom gender is less central. However, the qualitative meaning of these identities are likely to differ according to the historical experiences associated with the group.

Thus, it is imperative that any application of the MMRI to other groups only be done after a careful assessment of the model's compatibility with the historical and cultural experiences of the group in question. The four ideologies delineated by the MMRI are based specifically on our extensive study of the unique cultural and historical experiences of African Americans. Although the issues of assimilation and nationalism are relevant to other ethnic groups, there is a qualitative difference in the historical significance that these various philosophies have for different ethnic groups. For instance, there may be less tension around issues of assimilation for ethnic groups who have migrated to the United States looking for a better life as opposed to those who had American culture forced on them. Also, there may be group differences in the way that various ideologies are interrelated for various groups. There may be unique ideological profiles for African Americans based on their experiences. Similarly, the interrelation between the dimensions and other aspects of the self may also differ across groups as a result of the qualitative differences in the experiences of the groups. Rowley et al. (in press) have found evidence that the relation between public regard and personal self-esteem does not seem to be important for African Americans, while research with other ethnic groups suggests that such a relation is important (Crocker et al., 1994).

\section{Conclusions}

The MMRI is an integration of the mainstream and underground approaches. The MMRI has borrowed ideas from the mainstream perspective (e.g., concerning the role of racial identity in the context of other identities within the self-concept) and merged them with the underground approach's emphasis on the qualitative meaning of being Black. As a result, the MMRI is both "prescriptive" in proposing hypotheses for potential research questions regarding the structure and dynamics of racial identity in the self-concepts of African Americans and "descriptive" in proposing relevant dimensions in which to illustrate the complexity and variability that African Americans ascribe to being Black. It also has the potential to serve as a conceptual framework that could be adapted with care to the study of other group identities. In sum, the MMRI provides a vehicle for addressing new questions regarding African American racial identity that can contribute significantly to both the underground and mainstream approaches.

\section{References}

Abrams, D., Thomas, J., \& Hoggs, M. A. (1990). Numerical distinctiveness, social identity and gender salience. British Journal of Social Psychology, 29, 87-92.

Akbar, N. (1981). Mental disorders among African-Americans Blacks Books Bulletin, 7, 18-25.

Akbar, N. (1984). Africentric social science for human liberation. The Journal of Black Studies, 14, 395-414.

Akbar, N. (1989). Nigrescence and identity: Some limitations. The Counseling Psychologist, 17, 258-263.

Allport, G. (1954). The nature of prejudice. Cambridge, MA: Addison-Wesley.

Austin, N. L., Carter, R. T., \& Vaux, A. (1990). The role of racial identity in black student's attitudes toward counseling and counseling centers. Journal of College Student Development, 31, 237-244

Azibo, D. A. (1989). African-centered theses on mental health and a nosology of black African personality disorder. Journal of Black Psychology, 15, 173-214.

Azibo, D. A. (1991). Towards a metatheory of the African personality. The Journal of Black Psychology, 17, 37-45.

Baldwin, J. A. (1980). The psychology of oppression. In M. K. Asante \& A. Vandi (Eds.), Contemporary black thought (pp. 131-147) Beverly Hills, CA: Sage.

Baldwin, J. A. (1984). African self-consciousness and the mental health of African-Americans. Journal of Black Studies, 15 , 177-194.

Baldwin, J. A., \& Bell, Y. R. (1985). The African self-consciousness scale: An africentric personality questionnaire. Western Journal of Black Studies, 9, 61-68.

Baldwin, J. A., Brown, R., \& Rackley, R. (1990). Some socio-behavioral correlates of African self-consciousness in African-American college students. Journal of Black Psychology, 17, 1-17.

Baldwin, J. A., Duncan, J. A., \& Bell, Y. R. (1987). Assessment of African self-consciousness among black students from two college environments. Journal of Black Psychology, 13, 27-41.

Baldwin, J. A., \& Hopkins, R. (1990). Áfrican American and European-American cultural differences as assessed by the worldviews paradigm: An empirical analysis. Western Journal of Black Studies, 14, 38-52.

Banaji, M. R., \& Prentice, D. A. (1994). The self in social contexts Annual Review of Psychology, 45, 297-332.

Bargh, J. A., Bond, R. N., Lombardi, W. J., \& Tota, M. E. (1986) The additive nature of chronic and temporary sources of con- 
struct accessibility. Journal of Personality and Social Psychology, 50, 869-878.

Bargh, J., Lombardi, W. J., \& Higgins, E. T. (1988). Automaticity of chronically accessible constructs in person $\mathrm{X}$ situation effects on person perception: It's just a matter of time. Journal of Personality and Social Psychology, 55, 599-605.

Bargh, J. A., \& Pietromonaco, P. (1982). Automatic information processing and social perception: The influence of trait information presented outside of conscious awareness on impression formation. Journal of Personality and Social Psychology, 43

Bargh, J. A., \& Pratto, F. (1986). Individual construct accessibility and perceptual selection. Journal of Experimental Social Psychology, 22, 293-311.

Bargh, J. A., \& Thein, R. D. (1985). Individual construct accessibility, person memory, and the recall-judgment link: The case of information overload. Journal of Personality and Social Psychology, 49, 1129-1146.

Boykin, A. W. (1983). The academic performance of Afro-American children. In J. Spence (Ed.), Achievement and achievement motives (pp. 321-371). San Francisco: Freeman.

Broman, C. L., Jackson, J. S., \& Neighbors, H. W. (1989). Sociocultural context and racial group identification among black adults. Revue Internationale de Psychologie Sociale, 2, 367-378.

Cheek, J. M., \& Briggs, S. R. (1982). Self-consciousness and aspects of identity. Journal of Research in Personality, 16, 401-408.

Clark, K. B. (1965). Dark ghetto. New York: Harper \& Row.

Clark, K. B., \& Clark, M. P. (1939). The development of consciousness of self and the emergence of racial identification in Negro preschool children. Journal of Social Psychology, 10, 591-599.

Clark, K. B., \& Clark, M. P. (1947). Racial identification and preference in Negro children. In T. M. Newcomb \& E. L. Hartley (Eds.), Readings in social psychology (pp. 169-187). New York: Holt.

Cota, A. A., \& Dion, K. L. (1986). Salience of gender and sex composition of ad hoc groups: An experimental test of distinctiveness theory. Journal of Personality and Social Psychology, $50,770-776$

Crocker, J., \& Luhtanen, R. (1990). Collective self-esteem and ingroup bias. Journal of Personality and Social Psychology, 58, 60-67.

Crocker, J., Luhtanen, R., Blaine, B., \& Broadnax, S. (1994). Collective self-esteem and psychological well-being among white, black, and Asian college students. Personality and Social Psychology Bulletin, 20, 503-513.

Crocker, J., \& Major, B. (1989). Social stigma and self-esteem: The self-protective properties of stigma. Psychological Review, 96, 608-630.

Crocker, J., \& Schwartz, I. (1985). Prejudice and ingroup favoritism in a minimal intergroup situation: Effects of self-esteem. Personality and Social Psychology Bulletin, 11, 379-386.

Cross, W. E. (1971). Negro-to-Black conversion experience. Black World, 20, 13-27.

Cross, W. E. (1991). Shades of black: Diversity in African-American identity. Philadelphia: Temple University Press.

Deaux, K. (1993). Reconstructing social identity. Personality and Social Psychology Bulletin, 19, 4-12.

Demo, D. H., \& Hughes, M. (1990). Socialization and racial identity among Black Americans. Social Psychology Quarterly, 53, 364-374.

Devine, P. G., Evett, S. R., \& Vasquez-Suson, K. A. (1996). Exploring the interpersonal dynamics of intergroup contact. In R. M. Sorrentino \& E. T. Higgins (Eds.), Handbook of motivation and cognition (pp. 423-464). New York: Guilford.

DuBois, W. E. B. (1903). Souls of black folk. Chicago: A. C. McClurg.

Erikson, E. (1968). Identity: Youth and crisis. New York: Norton.

Ethier, K. A., \& Deaux, K. (1990). Hispanics in ivy: Assessing identity and perceived threat. Sex Roles, 22, 427-440.

Ethier, K. A., \& Deaux, K. (1994). Negotiating social identity when contexts change: Maintaining identification and responding to threat. Journal of Personality and Social Psychology, 67, 243-251.

Fazio, R. H. (1990). Multiple processes by which attitudes guide behavior: The mode model as an integrative framework. Advances in Experimental Social Psychology, 23, 75-109.

Fazio, R. H. (1986). How do attitudes guide behavior? In R. M Sorrentino \& E. T. Higgins (Eds.), Handbook of motivation and cognition foundations of social behavior (pp. 204-243). New York: Guilford.

Fazio, R. H., \& Zanna, M. P. (1981). Direct experience and attitudebehavior consistency. In L. Berkowitz (Ed.), Advances in experimental social psychology (Vol. 14, pp. 161-202). New York: Academic.

Gaines, S. O., \& Reed, E. S. (1994). Two social psychologies of prejudice: Gordon W. Allport, W. E. B. Du Bois, and the legacy of Booker T. Washington. Journal of Black Psychology, 20 , $8-28$.

Gaines, S. O., \& Reed, E. (1995). Prejudice: From Allport to Du Bois. American Psychologist, 50, 96-103.

Gurin, P., Hurtado, A., \& Peng, T. (1994). Group contacts and the ethnicity in the social identities of Mexicanos and Chicanos. Personality and Social Psychology Bulletin, 20, 521-532.

Gurin, P., \& Markus, H. (1988). Group identity: The psychological mechanisms of durable salience. Review Internationale de Psychologie Sociale, 1, 257-274.

Helms, J. E. (1984). Toward a theoretical explanation of the effects of race on counseling: A black and a white model. Counseling Psychologist, 12, 153-165.

Helms, J. E. (1990). Black and white racial identity: Theory, research, and practice. Westport, CT: Greenwood.

Higgins, E. T. (1989). Knowledge accessibility and activation: Subjectivity and suffering from unconscious sources. In J. S. Uleman \& J. A. Bargh (Eds.), Unintended thought (pp. 75-123). New York: Guilford.

Higgins, E. T. (1990). Personality, social psychology, and personsituation relations: Standards and knowledge activation as a common language. In L. A. Pervin (Ed.), Handbook of personality: Theory and research (pp. 301-338). New York: Guilford.

Higgins, E. T., King, G. A., \& Mavin, G. H. (1982). Individual construct accessibility and subjective impressions and recall. Journal of Personality and Social Psychology, 43, 35-47.

Higgins, E. T., Rholes, W. S., \& Jones, C. R. (1977). Category accessibility and impression formation. Journal of Experimental Social Psychology, 13, 141-154.

Hogg, M. A. (1992). The social psychology of group cohesiveness: From attraction to social identity. New York: Harvester Wheatsheaf.

Horowitz, E. L. (1936). The development of attitude toward the Negro. Archives of Psychology, 104.

Horowitz, R. (1939). Racial aspects of self-identification in nursery school children. Journal of Psychology, 7, 91-99.

Hughes, M., \& Demo, D. H. (1989). Self-perceptions of black Americans: Self-esteem and personal efficacy. American Journal of Sociology, 95, 132-159.

Ingram, B. J. (1989). Identity issues among African-American students in three university settings (Doctoral dissertation, Miami University, 1989). Dissertation Abstracts International, 50, 5318.

Jackson, L., \& Sullivan, L. (1987). The in-group favorability in the minimal groups situation. Journal of Social Psychology, 58, 60-67.

Jones, E. E., \& Gerard, H. B. (1967). Foundations of social psychology. New York: Wiley.

Kambon, K. (1992). The African personality in America: An Africancentered framework. Tallahassee, FL: Nubian Nation Publications.

Kardiner, A., \& Ovesey, L. (1951). The mark of oppression. New York: Norton.

Kelly, G. A. (1955). The psychology of personal constructs (Vols. 1-2). New York: Norton. 
Kite, M. E. (1992). Age and spontaneous self-concept. Journal of Applied Social Psychology, 22, 1828-1837.

Lazarus, R. S., \& Folkman, S. (1984). Stress, appraisal, and coping. New York: Springer.

Lewin, K. (1936). Principles of topological psychology. New York McGraw-Hill

Lewin, K. (1941). Jewish self-hatred. Contemporary Jewish Record, 4, 219-232.

Luhtanen, R., \& Crocker, J. (1992). A collective self-esteem scale: Self-evaluation of one's social identity. Personality and Social Psychology Bulletin, 18, 302-318.

Markus, H. (1977). Self-schemata and processing information about the self. Journal of Personality and Social Psychology, 35, 63-78.

Markus, H. (1983). Self-knowledge: An expanded view. Journal of Personality, 51, 543-564.

Markus, H., \& Kunda, Z. (1986). Stability and malleability of the self-concept. Journal of Personality and Social Psychology, 51, 858-866.

Markus, H., \& Nurius, P. (1986). Possible selves. American Psychologist, 41, 954-969.

Markus, H. \& Sentis, K. (1982). The self in social information processing. In J. Suls (Ed.), Psychological perspectives on the self (Vol. 1, pp. 41-70). Hillsdale, NJ: Lawrence Erlbaum Associates, Inc

Marriette, G. C. (1990). Racial identity attitudes as predictors of ego functions/defense mechanisms in African American adult school students. Unpublished doctoral dissertation, California Graduate Institute, Los Angeles

McAdoo, H. P. (1985). Racial attitude and self-concept of young black children over time. In H. P. McAdoo and J. L. McAdoo (Eds.), Black children: Social, educational, and parental environments (pp. 213-242). Beverly Hills, CA: Sage.

McCall, G. J., \& Simmons, J. T. (1978). Identities and interaction. New York: Free Press.

McCrae, R. R., \& Costa, P. T. (1988). Age, personality, and spontaneous self-concept. Journal of Gerontology, 46, 177-185.

McGuire, W. J., \& McGuire, C. V. (1982). Significant others in self space: Sex differences and developmental trends in social life. In J. Suls (Ed.), Psychological perspectives on the self (Vol. 1, pp. 71-96). Hillsdale, NJ: Lawrence Erlbaum Associates, Inc.

McGuire, W. J., McGuire, C. V., Child, P., \& Fujioka, T. (1978). Salience of ethnicity in the spontaneous self-concept as a function of one's ethnic distinctiveness in the social environment. Journal of Personality and Social Psychology, 36, 511-520.

McGuire, W. J., McGuire, C. V., \& Winton, W. (1979). Effects of household sex composition on the salience of one's gender in the spontaneous self-concept. Journal of Experimental Social Psychology, 15, 77-90.

McGuire, W. J., \& Padawer-Singer, A. (1976). Trait salience in the spontaneous self-concept. Journal of Personality and Social Psychology, 33, 743-754.

Mead, G. H. (1934). Mind, self, and society. Chicago: University of Chicago Press

Messick, D. M., \& Mackie, D. M. (1989). Intergroup relations. Annual Review of Psychology, 40, 45-81

Milliones, J. (1976, October). The Pittsburgh Project-Part II: Construction of a black consciousness measure. Paper presented at the Third Conference on Empirical Research in Black Psychology, Ithica, New York.

Milliones, J. (1980). Construction of a black consciousness measure: Psychotherapeutic implications. Psychotherapy: Theory, Research, and Practice, 17, 175-182.

Nobles, W. A. (1991). African philosophy: Foundations for black psychology. In R. L. Jones (Ed.), Black Psychology (3rd ed., pp. 47-63). Berkeley, CA: Cobb and Henry Publishers.

Nunnally, J. C., \& Bernstein, I. H. (1994). Psychometric theory (3rd ed.). New York: McGraw-Hill.

Oakes, P. J., Haslam, S. A., \& Turner, J. C. (1994). Stereotyping and social reality. Cambridge, MA: Basil Blackwell.
Oyserman, D., Gant, L., \& Ager, J. (1995). A socially contextualized model of African American identity: Possible selves and school persistence. Journal of Personality and Social Psychology, 69, $1216-1232$.

Parham, T. A. (1989). Cycles of psychological nigrescence. The Counseling Psychologist, 17, 187-226.

Parham, T. A., \& Helms, J. E. (1981). The influences of a black students' racial identity attitudes on preference for counselor's race. Journal of Counseling Psychology, 28, 250-256.

Parham, T. A., \& Helms, J. E. (1990). Black racial identity scale. In J. E. Helms (Ed.), Black and White racial identity: Theory, research, and practice (pp. 245-247). Westport, CT: Greenwood.

Parham, T. A., \& Helms, J. E. (1985). Relation of racial identity attitudes to self-actualization and affective states of black students. Journal of Counseling Psychology, 32, 431-440.

Parham, T. A., \& Williams, P. T. (1993). The relationship of demographic and background factors to racial identity attitudes. Journal of Black Psychology, 19, 7-24

Penn, M. L., Gaines, S. O., \& Phillips, L. (1993). On the desirability of own-group preference. Journal of Black Psychology, 19, 303-321.

Phinney, J. S. (1989). Stages of ethnic identity development in minority group adolescents. Journal of Early Adolescence, 9, $34-49$.

Phinney, J. S. (1990). Ethnic identity in adolescence and adulthood: A review and integration. Psychological Bulletin, 108, 499-514.

Phinney, J. S. (1992). The Multigroup Ethnic Identity Measure: A new scale for use with diverse groups. Journal of Adolescent Research, 7, 156-172.

Phinney, J. S., \& Alipuria, L. L. (1990). Ethnic identity in college students from four ethnic groups. Journal of Adolescence, 13, $171-183$

Ponterotto, J. G., \& Wise, S. L. (1987). Construct validity study of the Racial Identity Attitude Scale. Journal of Counseling Psychology, 34, 218-223.

Rosenberg, M. (1979). Group rejection and self-rejection. Research in Community Mental Health, 1, 3-20.

Rowley, S. A. J., Sellers, R. M., Chavous, T. M., \& Smith, M. A. (in press). The relationship between racial identity and self-esteem in African American college and high school students. Journal of Personality and Social Psychology.

Sellers, R. M. (1993). A call to arms for researchers studying racial identity. Journal of Black Psychology, 19, 327-332.

Sellers, R. M., Chavous, T. M., \& Cooke, D. Y. (in press). Racial ideology and racial centrality as predictors of African American college students' academic performance. Journal of Black Psychology.

Sellers, R. M., Rowley, S. A. J., Chavous, T. M., Shelton, J. N., \& Smith, M. (1997). Multidimensional Inventory of Black Identity: Preliminary investigation of reliability and construct validity. Journal of Personality and Social Psychology, 73, 805-815.

Shelton, J. N., \& Sellers, R. M. (1996). Situational stability and variability in African American racial identity. Manuscript submitted for publication, University of Virginia, Charlottesville.

Smith, E. (1989). Black racial identity development: Issues and concerns. The Counseling Psycholagist, 17, 277-288.

Smith, E. J. (1991). Ethnic identity development: Toward the development of a theory within the context of majority/minority status. Journal of Counseling and Development, 70, 181-188.

Steele, C. M. (1997). A threat in the air: How stereotypes shape intellectual identity and performance. American Psychologist $52,613-629$.

Steele, C. M., \& Aronson, J. (1995). Stereotype threat and intellectual test performance of African Americans. Journal of Personality and Social Psychology, 69, 797-811.

Stryker, S. (1980). Symbolic interactionism: A social structural version. Menlo Park, CA: Benjamin Cummings. 
Stryker, S., \& Serpe, R. T. (1982). Commitment, identity salience and role behavior. In W. Ickes \& E. Knowles (Eds.), Personality, roles, and social behavior (pp. 199-218). New York: Springer-Verlag.

Stryker, S., \& Serpe, R. T. (1994). Identity salience and psychological centrality: Equilavent, overlapping, or complementary concepts? Social Psychology Quarterly, 57, 16-35.

Swan, W. B., \& Read, S. J. (1981). Acquiring self-knowledge: The search for feedback that fits. Journal of Personality and Social Psychology, 41, 1119-1128.

Terrell, F., \& Terrell, S. L. (1981). An inventory to measure cultural mistrust among blacks. Western Journal of Black Studies, 5 , 180-184.

Turner, J. C., \& Oakes, P. J. (1989). Self-categorization theory and social influence. In P. B. Paulus (Ed.), The psychology of group influence (2nd ed., pp. 233-275). Mahwah, NJ: Lawrence Erlbaum Associates, Inc.

Turner, J. C., Oakes, P. J., Haslam, S. A., \& McGarty, C. (1994). Self and collective: Cognition and social context. Personality and Social Psychology Bulletin, 20, 454-463.

Turner, R. (1978). The role and the person. American Journal of Sociology, 84, 1-23.

Weiner, B. (Ed.). (1974). Cognitive views of human emotion. New York: Academic.

White, C. L., \& Burke, P. J. (1987). Ethnic role identity among black and white college students: An interactionist approach. Sociological Perspectives, 30, 310-331.

White, J. L., \& Parham, T. A. (1990). The psychology of blacks: An African-American perspective. New Jersey: Prentice-Hall.

\section{Appendix: The Multidimensional Inventory of Black Identity}

\section{Centrality Scale $^{\mathrm{a}}$}

1. Overall, being Black has very little to do with how I feel about myself. (R)

2. In general, being Black is an important part of my self-image.

3. My destiny is tied to the destiny of other Black people.

4. Being Black is unimportant to my sense of what kind of person I am. (R)

5. I have a strong sense of belonging to Black people.

6. I have a strong attachment to other Black people.

7. Being Black is an important reflection of who I am.

8. Being Black is not a major factor in my social relationships. (R)

\section{Regard Scale}

\section{Private Regard Subscale}

1. I feel good about Black people.

2. I am happy that I am Black.

3. I feel that Blacks have made major accomplishments and advancements.

4. I often regret that I am Black. (R)
5. I am proud to be Black.

6. I feel that the Black community has made valuable contributions to this society.

\section{Public Regard Subscale}

1. Overall, Blacks are considered good by others.

2. In general, others respect Black people.

3. Most people consider Blacks, on the average, to be more ineffective than other racial groups. ( $\mathrm{R}$ )

4. Blacks are not respected by the broader society. (R)

5. In general, other groups view Blacks in a positive manner.

6. Society views Black people as an asset.

a $(R)$ items should be reverse coded.

\section{Ideology Scale}

\section{Assimilation Subscale}

1. Blacks who espouse separatism are as racist as White people who also espouse separatism.

2. A sign of progress is that Blacks are in the mainstream of America more than ever before.

3. Because America is predominantly White, it is important that Blacks go to White schools so that they can gain experience interacting with Whites.

4. Blacks should strive to be full members of the American political system.

5. Blacks should try to work within the system to achieve their political and economic goals.

6. Blacks should strive to integrate all institutions which are segregated.

7. Blacks should feel free to interact socially with White people.

8. Blacks should view themselves as being Americans first and foremost.

9. The plight of Blacks in America will improve only when Blacks are in important positions within the system.

\section{Humanist Subscale}

1. Black values should not be inconsistent with human values.

2. Blacks should have the choice to marry interracially.

3. Blacks and Whites have more commonalties than differences.

4. Black people should not consider race when buying art or selecting a book to read. 
5. Blacks would be better off if they were more concerned with the problems facing all people than just focusing on Black issues.

6. Being an individual is more important than identifying oneself as Black.

7. We are all children of a higher being, therefore, we should love people of all races.

8. Blacks should judge Whites as individuals and not as members of the White race.

9. People regardless of their race have strengths and limitations.

\section{Oppressed Minority Subscale}

1. The same forces which have led to the oppression of Blacks have also led to the oppression of other groups.

2. The struggle for Black liberation in America should be closely related to the struggle of other oppressed groups.

3. Blacks should learn about the oppression of other groups.

4. Black people should treat other oppressed people as allies.

5. The racism Blacks have experienced is similar to that of other minority groups.

6. There are other people who experience racial injustice and indignities similar to Black Americans.
7. Blacks will be more successful in achieving their goals if they form coalitions with other oppressed groups.

8. Blacks should try to become friends with people from other oppressed groups.

9. The dominant society devalues anything not White male oriented.

\section{Nationalist Subscale}

1. It is important for Black people to surround their children with Black art, music and literature.

2. Black people should not marry interracially.

3. Blacks would be better off if they adopted Afrocentric values.

4. Black students are better off going to schools that are controlled and organized by Blacks.

5. Black people must organize themselves into a separate Black political force.

6. Whenever possible, Blacks should buy from other Black businesses.

7. A thorough knowledge of Black history is very important for Blacks today.

8. Blacks and Whites can never live in true harmony because of racial differences.

9. White people can never be trusted where Blacks are concerned.

Note: Response scale ranges from 1 (Strongly Disagree) to 7 (Strongly Agree). 